\title{
BMJ Open Association between organ damage and mortality in systemic lupus erythematosus: a systematic review and meta-analysis
}

\author{
Irene B Murimi-Worstell, ${ }^{1,2}$ Dora H Lin, ${ }^{3}$ Henk Nab, ${ }^{4}$ Hong J Kan, ${ }^{5}$ \\ Oluwadamilola Onasanya, ${ }^{2,6}$ Jonothan C Tierce, ${ }^{1,2}$ Xia Wang, ${ }^{7}$ Barnabas Desta, ${ }^{7}$ \\ G Caleb Alexander, ${ }^{1,2,8}$ Edward R Hammond $^{7}$
}

To cite: Murimi-Worstell IB, $\mathrm{Lin} \mathrm{DH}, \mathrm{Nab} \mathrm{H}$, et al. Association between organ damage and mortality in systemic lupus erythematosus: a systematic review and meta-analysis. BMJ Open 2020;10:e031850. doi:10.1136/ bmjopen-2019-031850

- Prepublication history and additional material for this paper are available online. To view these files, please visit the journal online (http://dx.doi org/10.1136/bmjopen-2019031850).

Received 22 May 2019 Revised 26 March 2020 Accepted 09 April 2020

Check for updates

(c) Author(s) (or their employer(s)) 2020. Re-use permitted under CC BY-NC. No commercial re-use. See rights and permissions. Published by BMJ.

For numbered affiliations see end of article.

Correspondence to Dr Edward R Hammond; edward.hammond@ astrazeneca.com

\section{ABSTRACT}

Objective At least half of patients with systemic lupus erythematosus (SLE) develop organ damage as a consequence of autoimmune disease or long-term therapeutic steroid use. This study synthesised evidence on the association between organ damage and mortality in patients with SLE.

Design Systematic review and meta-analysis. Methods Electronic searches were performed in PubMed, Embase, Cochrane Library and Latin American and Caribbean Health Sciences Literature for observational (cohort, case-control and cross-sectional) studies published between January 2000 and February 2017. Included studies reported HRs or ORs on the association between organ damage (measured by the Systemic Lupus International Collaborating Clinics/ American College of Rheumatology Damage Index (SDI) score) and mortality. Study quality was assessed using the modified Newcastle-Ottawa assessment. Pooled HRs were obtained using the DerSimonian and Laird randomeffects model. Heterogeneity was assessed using the Cochrane $Q(Q)$ and $I^{2}$ statistics.

Results The search yielded 10420 articles, from which 21 longitudinal studies were selected. Most studies $(85 \%)$ were of high quality. For 10 studies evaluating organ damage (SDI) as a continuous variable and reporting $\mathrm{HR}$ as a measure of association, a 1-unit increase in SDI was associated with increased mortality; pooled HR was 1.34 (95\% Cl: 1.24 to $1.44, \mathrm{p}<0.001 ; \mathrm{Q}$ $p=0.027, I^{2}=52.1 \%$ ). Exclusion of one potential outlying study reduced heterogeneity with minimal impact on pooled HR (1.33 (95\% Cl: 1.25 to 1.42), $p<0.001$, $\left.Q p=0.087, I^{2}=42.0 \%\right)$. The 11 remaining studies, although they could not be aggregated because of their varying patient populations and analyses, consistently demonstrated that greater SDI was associated with increased mortality.

Conclusions Organ damage in SLE is consistently associated with increased mortality across studies from various countries. Modifying the disease course with effective therapies and steroid-sparing regimens may reduce organ damage, improve outcomes and decrease mortality for patients with SLE.

\section{Strengths and limitations of this study}

- We report a systematic review with meta-analysis of high-quality studies across four continents that demonstrates a consistent association between systemic lupus erythematosus (SLE)-related organ damage and increased mortality.

- To our knowledge, this is the first meta-analysis informed by a systematic literature review investigating the association between organ damage, assessed by SDI (Systemic Lupus International Collaborating Clinics/American College of Rheumatology Damage Index), and mortality in patients with SLE.

- A meta-analysis was performed on 10 of 21 identified studies because of variations in methods used across studies; however, we observed consistency in the association between organ damage and mortality across multiple study design types with varying analytical methods.

- Although our search strategy was limited to studies published between 2000 and 2017, it is unlikely that inclusion of studies published after 2017 would change the observed result significantly, because of the consistency of the association between organ damage and mortality informed by the long patient follow-up periods of the studies analysed.

- Statistical evidence of study heterogeneity was identified, potentially attributable to the few studies included in the meta-analysis; however, exclusion of a potential outlying study reduced between-study heterogeneity to moderate, with minimal impact on the pooled association between organ damage and mortality.

\section{INTRODUCTION}

Systemic lupus erythematosus (SLE) is an inflammatory autoimmune disease with a reported prevalence of 20 to 150 cases per 100000 persons. ${ }^{1}$ SLE is a chronic and debilitating disease characterised by flares, progressive end organ damage ${ }^{2}$ and increased mortality. ${ }^{3}$ SLE affects multiple organ systems, ${ }^{1}$ including the kidneys, the skin, and 
the cardiovascular, musculoskeletal and central nervous systems. ${ }^{4}$ Approximately half of all patients with SLE will have some form of organ damage within 10 years of their diagnosis. ${ }^{5}$ Furthermore, patients with SLE experience a higher rate of mortality and earlier mortality than the general population. ${ }^{6}$

SLE mortality is an important outcome to patients and providers and may be affected by accumulation of SLErelated organ damage. Organ damage potentially occurs through several different mechanisms. Hyperactive B cells are known to increase the formation and deposition of autoantibodies and immune complexes, which induce inflammatory tissue damage in the microvasculature. ${ }^{1}$ In addition, long-term corticosteroid use is associated with an increased risk for the accumulation of organ damage, such as osteoporosis and cardiovascular disease. ${ }^{78}$ Despite well-recognised adverse effects, corticosteroids are still widely used, in part because there is no optimal treatment for SLE.

Published literature suggests that the extent of accumulated organ damage in patients with SLE is associated with poorer health outcomes, including decreased physical functioning, reduced health-related quality of life and increased mortality. ${ }^{39}$ Although there have been studies that report mortality in patients with SLE and organ damage, the extent to which organ damage is associated with increased mortality is unknown. We sought to aggregate available evidence on the association between organ damage, as measured by the Systemic Lupus International Collaborating Clinics/ American College of Rheumatology Damage Index (SDI), a validated instrument designed to measure irreversible damage in 12 different organ systems in patients with SLE, and risk of mortality through systematic review and meta-analysis.

\section{METHODS AND ANALYSIS}

This systematic literature review and meta-analysis is reported in accordance with the Preferred Reporting Items for Systematic Reviews and Meta-Analyses statement guidelines. ${ }^{10}$ Methods of the inclusion criteria and analysis were specified in advance and documented in a study protocol, which underwent internal organisational review and approval prior to study initiation.

\section{Literature search and screen}

A systematic literature search of PubMed, Embase, Cochrane Library and Latin American and Caribbean Health Sciences Literature was performed to identify studies published between January 2000 and February 2017 that evaluated the association between organ damage (measured by SDI) and mortality, and the association between organ damage and health-related quality of life, in adults with SLE. This report presents findings on the association between organ damage and mortality. Results regarding the association between organ damage and health-related quality of life have been presented separately. ${ }^{11}$ Search terms were chosen based on relevant free text keywords and Medical Subject Headings or Emtree-controlled vocabulary related to SLE and mortality. Details of the search terms for each database are provided in online supplementary appendix 1. Handsearching and citation review of relevant studies were conducted but did not identify additional studies that were not captured by the electronic database search.

Inclusion criteria included observational and casecontrol studies, cross-sectional studies and systematic reviews. Exclusion criteria included the following: nonEnglish language articles, study designs that did not report original, population-level measures of association and studies of patients $<18$ years of age. Case series, case reports and studies with limited populations that are not generalisable were also excluded. Full inclusion/ exclusion criteria are provided in online supplementary appendix 2. Clarivate Analytics EndNote X7 was used to organise the study titles and abstracts downloaded from the databases. One reviewer screened article titles and abstracts for selection according to inclusion and exclusion criteria. After article selection was complete, a panel of three investigators, working independently, re-examined $20 \%$ of the included articles to validate the quality of the initial selection process. Once validated, a full-text screening was conducted by two reviewers working independently to obtain the final set of articles.

\section{Data extraction}

Data extraction was performed by two independent reviewers, and discordances were adjudicated by a third independent reviewer. Data extraction forms were created for capturing study characteristics and outcomes reported in the identified studies, including characteristics such as the study country, organ damage, baseline SDI scores and duration of follow-up, which would inform interpretation of the associations of interest. Study quality was assessed using the modified Newcastle-Ottawa quality assessment scale. $^{12}$

\section{Data synthesis and meta-analysis}

The primary quantitative analyses focussed on longitudinal cohort studies that assessed the risk of mortality per unit change in SDI. Pooled HRs were obtained using the DerSimonian and Laird random-effects model. A narrative evidence synthesis approach was used for studies that evaluated organ damage as binary based on varying SDI cut-points $(\mathrm{SDI}=0$ vs $>0$; $\mathrm{SDI}<2$ vs $\geq 2$; $\mathrm{SDI}<3$ vs $\geq 3$ or $\mathrm{SDI}<5$ vs $\geq 5$ ) and that also reported varying measures of association, ORs and HRs. ${ }^{513-32}$ Heterogeneity was assessed across studies using the Cochrane $\mathrm{Q}$ and $\mathrm{I}^{2}$ statistics, with consideration given to clinical judgement. Cochrane $\mathrm{Q}$ tests with $\mathrm{P}$ values $<0.10$ suggest statistically significant heterogeneity, whereas cut-offs of $25 \%, 50 \%$ and $75 \%$ on the $\mathrm{I}^{2}$ statistic are routinely used to demarcate low, medium and high levels of heterogeneity, respectively. ${ }^{33-35}$ Sensitivity 


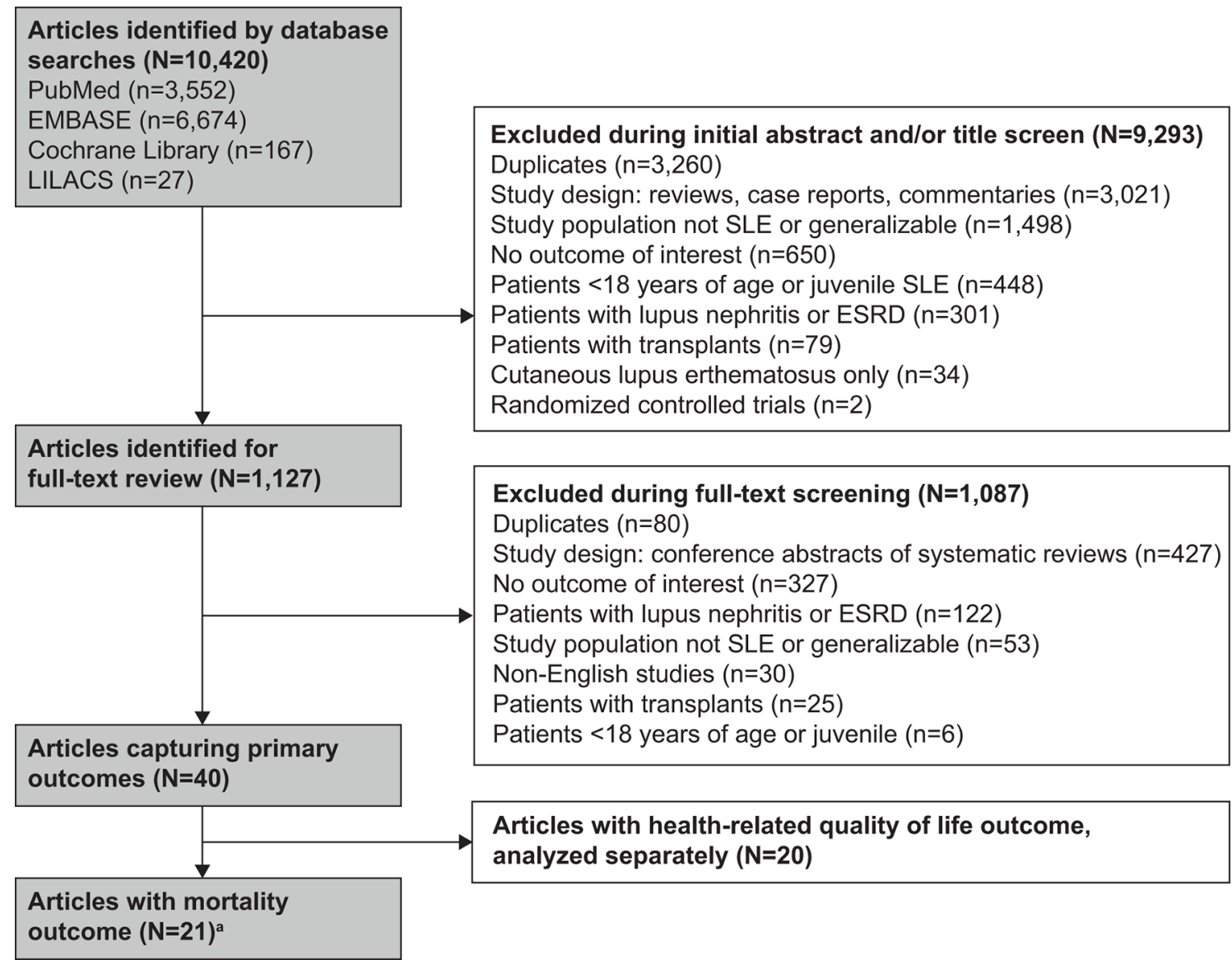

Figure 1 Flowchart of screening process. ${ }^{\mathrm{a} O}$ One study included both health-related quality of life and mortality outcomes. Quality of life will be reported separately. ESRD, end-stage renal disease; LILACS, Latin American and Caribbean Health Sciences Literature; SLE, systemic lupus erythematosus.

analyses were performed to assess the effect of studies with outlying effect estimates. A funnel plot of included studies that reported HRs was visually inspected and Egger's test was used to quantify publication bias, where $\mathrm{p}<0.05$ was considered statistically significant.

\section{Patient and public involvement}

Neither patients nor the public were involved in the design and conduct of the study. Dissemination of our findings, however, targets a wide audience including patients and members of the public and those who read peer-reviewed publications.

\section{RESULTS}

\section{Characteristics of included studies}

The combined literature search for mortality and healthrelated quality of life outcomes yielded 10420 articles. We identified 1127 articles for full-text review. A total of 21 longitudinal cohort studies were selected that evaluated the association between organ damage and mortality in patients with SLE (figure 1). ${ }^{5}{ }^{13-32}$ Table 1 summarises key characteristics of these 21 identified studies (more detailed study characteristics are provided in online supplementary appendix 3). A total of 20 studies were identified that examine the association between organ damage and quality of life; these findings will be published separately.

The selected studies varied by sample size (ranging from 105 to 1241 patients), geographical location, duration of follow-up and methods by which the association between organ damage measured by SDI and mortality was evaluated..$^{5}{ }^{13-32}$ Five studies reported on populations from North America; ${ }^{16} 28293132$ the remaining 16 reported on populations from Asia, ${ }^{15202126}$ Europe $^{517-19252730}$ or South America ${ }^{142324}$ or on populations across continents. ${ }^{1322}$ In 11 of the 21 studies, the mean or median reported age of participants (at either study enrolment, SLE onset or SLE diagnosis) was between 30 and 40 years,; ${ }^{5} 14$ 16-1922 27293032 six studies contained study groups (eg, patients with late-onset SLE) with a mean or median age $>40$ years, ${ }^{13} 2124-2632$ and four contained study groups with mean age $<30$ years. $^{15202331}$ The populations studied were predominantly female ( $78 \%$ to $97 \%$ ). The follow-up periods varied across studies-the shortest mean and median follow-up periods were 1.7 years $^{23}$ and 3.3 years, ${ }^{14}$ respectively. The longest mean and median follow-up periods were 36 years ${ }^{16}$ and 26 years, ${ }^{13}$ respectively. 
Table 1 Longitudinal studies examining the association between organ damage (measured by SDI) and mortality in patients with SLE, shown by use of SDI as continuous variable or binary category ( $n=21$ studies)

\begin{tabular}{|c|c|c|c|c|c|c|c|}
\hline Author (year) & $\begin{array}{l}\text { Last year } \\
\text { of data } \\
\text { collection }\end{array}$ & Sample size & $\begin{array}{l}\text { Follow-up } \\
\text { duration (years), } \\
\text { mean (median) } \\
\text { [SD or range] }\end{array}$ & $\begin{array}{l}\text { Baseline SDI, } \\
\text { mean (median) } \\
\text { [SD or range] }\end{array}$ & \multicolumn{3}{|c|}{$\begin{array}{l}\text { Associations between organ damage (SDI) and } \\
\text { mortality }\end{array}$} \\
\hline Mok et $a l^{26}$ & 2003 & $\begin{array}{l}\text { aSLE: } 213 \\
\text { LSLE: } 22 \\
\text { All: } 285\end{array}$ & $\operatorname{Max} 13$ & $\begin{array}{l}\text { Year } 1 \\
\text { aSLE: } 0.4[0.7] \\
\text { LSLE: } 1.0[1.1]\end{array}$ & 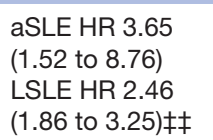 & $\begin{array}{l}\text { 1-point SDI } \\
\text { increase in } \\
\text { Year } 1\end{array}$ & $\begin{array}{l}\text { Age, antibody, major } \\
\text { organ disease, med } \\
\text { dose, med use, sex, } \\
\text { SLEDAI }\end{array}$ \\
\hline Fernández et $a / \ddagger^{28}$ & NS & 552 & NS & $\begin{array}{l}F: 1.7(1) \\
M: 2.0(1)\end{array}$ & $\begin{array}{l}\text { F HR } 1.20 \\
(1.00 \text { to } 1.44) \\
\text { M HR } 1.48 \\
(1.28 \text { to } 1.72) \neq \ddagger\end{array}$ & $\begin{array}{l}\text { 1-point SDI } \\
\text { increase }\end{array}$ & $\begin{array}{l}\text { Age, poverty, race, } \\
\text { sex, SF-6D, SLE } \\
\text { activity }\end{array}$ \\
\hline Urowitz et $a l^{16}$ & 2005 & $\begin{array}{l}\text { All: } 1241 \\
\text { I: } 228 \\
\text { II: } 364 \\
\text { III: } 260 \\
\text { IV: } 389\end{array}$ & $\begin{array}{l}\text { [9-36] } \\
\text { I: } 36 \\
\text { II: } 27 \\
\text { III: } 18 \\
\text { IV: } 9\end{array}$ & $\begin{array}{l}\text { I: } 0.4[0.9] \\
\text { II: } 0.3[0.8] \\
\text { III: } 0.3[0.9] \\
\text { IV: } 0.2[0.8]\end{array}$ & $\begin{array}{l}\text { HR } 1.24 \\
\text { (1.14 to } 1.35)\end{array}$ & $\begin{array}{l}\text { 1-point SDI } \\
\text { increase }\end{array}$ & $\begin{array}{l}\text { Age, AMS, entry } \\
\text { cohort, race, sex, } \\
\text { calendar period }\end{array}$ \\
\hline Cardoso et a/ $\|^{24}$ & 2007 & $\begin{array}{l}\text { Alive: } 86 \\
\text { Died: } 19 \\
\text { All: } 105\end{array}$ & $\begin{array}{l}(6.3) \\
{[0.3-7.0]}\end{array}$ & $\mathrm{SDI}=0: 18 \%$ & $\begin{array}{l}\text { Baseline HR } \\
1.34 \\
(1.14 \text { to } 1.58) \\
\text { Study end } \mathrm{HR} \\
1.35 \\
(1.16 \text { to } 1.57)\end{array}$ & $\begin{array}{l}\text { 1-point SDI } \\
\text { increase }\end{array}$ & Age, sex, SLE duration \\
\hline Kang et $a 1^{15}$ & 2007 & 1010 & $\operatorname{Max} 11$ & $0.5[1.0]$ & $\begin{array}{l}\text { OR } 19.7 \\
\text { (5.3 to } 72.5)\end{array}$ & $\begin{array}{l}\text { 1-point SDI } \\
\text { increase }\end{array}$ & $\begin{array}{l}\text { Age, med dose, med } \\
\text { use }\end{array}$ \\
\hline Lopez et $a l^{\star \star 27}$ & NS & 350 & (9) & $\begin{array}{l}\mathrm{SDI}<3: 97 \% \\
\mathrm{SDI}=0: 73 \% \\
\mathrm{SDI}=1: 18 \% \\
\mathrm{SDI} \geq 2: 9 \%\end{array}$ & $\begin{array}{l}\text { HR } 1.70 \\
(p=0.001)\end{array}$ & $\begin{array}{l}\text { 1-point SDI } \\
\text { increase }\end{array}$ & $\begin{array}{l}\text { Age, BILAG, ethnicity, } \\
\text { med use, race, sex, } \\
\text { SLE duration }\end{array}$ \\
\hline Gafter-Gvili et al ${ }^{21}$ & 2010 & 143 & $\begin{array}{l}9.4(9.0) \\
{[3.3,1-19]}\end{array}$ & $0.9[0-1.1]$ & $\begin{array}{l}\text { HR } 1.28 \\
\text { (1.08 to } 1.50)\end{array}$ & $\begin{array}{l}\text { 1-point SDI } \\
\text { increase }\end{array}$ & Age, biomarker, sex \\
\hline Telles et $a l^{14}$ & 2009 & 179 & $\begin{array}{l}(3.3) \\
{[3.1-3.5]}\end{array}$ & $\mathrm{SDI} \geq 3: 26 \%$ & $\begin{array}{l}\operatorname{HR} 1.40 \\
(1.08 \text { to } 1.82)\end{array}$ & $\begin{array}{l}\text { 1-point SDI } \\
\text { increase }\end{array}$ & APS, med use \\
\hline Bruce et $\mathrm{al}^{22}$ & NS & 671 & NS & $\mathrm{SDI}=0: 81 \%$ & $\begin{array}{l}\operatorname{HR} 1.46 \\
(1.18 \text { to } 1.81)\end{array}$ & $\begin{array}{l}\text { 1-point SDI } \\
\text { increase }\end{array}$ & NS \\
\hline Joo et $a^{20}$ & 2012 & 979 & $\begin{array}{l}7.2 \\
{[4.3,0-15]}\end{array}$ & $0.9[1.5,0-9]$ & $\begin{array}{l}\text { HR } 1.2 \\
\text { (1.0 to } 1.4)\end{array}$ & $\begin{array}{l}\text { 1-point SDI } \\
\text { increase }\end{array}$ & $\begin{array}{l}\text { Age, AMS, antibody, } \\
\text { cSLE, sex, SLE } \\
\text { duration }\end{array}$ \\
\hline \multicolumn{8}{|c|}{ SDI analysed as a binary category } \\
\hline Manger et $a l^{19}$ & 1999 & 338 & $(5.4)$ & Year $1(2)$ & $\begin{array}{l}\text { RR } 7.7 \\
\text { (3.3 to } 18.6)\end{array}$ & $\begin{array}{l}\triangle \mathrm{SDI}<2, \text { Year } \\
1-3\end{array}$ & $\begin{array}{l}\text { Age, antibody } \\
\text { comorbidities, sex }\end{array}$ \\
\hline
\end{tabular}


Table 1 Continued

\begin{tabular}{|c|c|c|c|c|c|c|c|}
\hline \multirow[b]{2}{*}{ Author (year) } & \multirow{2}{*}{$\begin{array}{l}\text { Last year } \\
\text { of data } \\
\text { collection }\end{array}$} & \multirow[b]{2}{*}{ Sample size } & \multirow{2}{*}{$\begin{array}{l}\text { Follow-up } \\
\text { duration (years), } \\
\text { mean (median) } \\
\text { [SD or range] }\end{array}$} & \multirow{2}{*}{$\begin{array}{l}\text { Baseline SDI, } \\
\text { mean (median) } \\
\text { [SD or range] }\end{array}$} & \multicolumn{3}{|c|}{$\begin{array}{l}\text { Associations between organ damage (SDI) and } \\
\text { mortality }\end{array}$} \\
\hline & & & & & $\begin{array}{l}\text { Estimator } \\
(95 \% \mathrm{Cl})^{\star}\end{array}$ & $\begin{array}{l}\text { Reference } \\
\text { group }\end{array}$ & Covariates $\uparrow$ \\
\hline Pons-Estel et $a l^{23}$ & 2000 & 1214 & $\begin{array}{l}(1.7) \\
{[0-13.5]}\end{array}$ & $\begin{array}{l}0.6[1.1] \S \\
\text { SDI=0: } 66 \% \S\end{array}$ & $\begin{array}{l}\text { OR } 2.8 \\
(1.2 \text { to } 6.4) \S\end{array}$ & $\mathrm{SDI}=0$ & $\begin{array}{l}\text { Age, country, } \\
\text { coverage, diagnosis } \\
\text { delay, education, ever } \\
\text { hospitalised, marital } \\
\text { status, SES, sex }\end{array}$ \\
\hline Becker-Merok et al ${ }^{18}$ & NS & 158 & $11.9(10.2)$ & $\begin{array}{l}(1.26)[0-8] \S \\
\text { SDI }=0: 97 \%\end{array}$ & $\begin{array}{l}\text { HR } 1.44(0.67 \text { to } \\
3.09) \S\end{array}$ & $\mathrm{SDI}<3$ & $\begin{array}{l}\text { Age, sex, SLEDAI, } \\
\text { SLEDAI weighted } \\
\text { average }\end{array}$ \\
\hline Cardoso et $a / \eta^{24}$ & 2007 & $\begin{array}{l}\text { Alive: } 86 \\
\text { Died: } 19 \\
\text { All: } 105\end{array}$ & $\begin{array}{l}(6.3) \\
{[0.3-7.0]}\end{array}$ & $\mathrm{SDI}=0: 18 \%$ & $\begin{array}{l}\text { Baseline HR } \\
3.05 \\
(1.13 \text { to } 8.23) \\
\text { Study end HR } \\
4.74 \\
\text { (1.55 to } 14.51) \\
\text { All HR } 5.10 \\
\text { (1.99 to } 13.03)\end{array}$ & $\begin{array}{l}\mathrm{SDl}<3 \\
\triangle \mathrm{SDI}=0\end{array}$ & Age, sex, SLE duration \\
\hline Danila et $a / \ddagger^{29}$ & NS & 635 & NS & $\begin{array}{l}\text { Renal SDI>0: } \\
20 \% \\
\text { CV SDI>0: } 9 \%\end{array}$ & $\begin{array}{l}\text { Renal SDI HR } \\
1.65 \\
(1.03 \text { to } 2.66) \\
\text { CV SDI HR } 1.55 \\
\text { (0.94 to } 2.56)\end{array}$ & $\begin{array}{l}\text { Renal SDI }=0 \\
\text { CV SDI }=0\end{array}$ & $\begin{array}{l}\text { Age, poverty, race, } \\
\text { sex, SLAMR }\end{array}$ \\
\hline Gustafsson et $a l^{30}$ & 2010 & 208 & 12.3 & $\mathrm{SDI} \leq 1: 41 \%$ & $\begin{array}{l}\text { HR } 3.8 \\
(1.3 \text { to } 16.4)\end{array}$ & $\mathrm{SDI}<2$ & $\begin{array}{l}\text { Age, arterial disease, } \\
\text { biomarker }\end{array}$ \\
\hline $\begin{array}{l}\text { Martínez-Barrio et } \\
a l^{25}\end{array}$ & 2012 & $\begin{array}{l}\text { aSLE: } 276 \\
\text { LSLE: } 77\end{array}$ & 26 & $\begin{array}{l}\text { Mean [SD]/ } \\
\text { SDI=0 } \\
\text { aSLE: } 1.7 \\
\text { [2.0]/36\% } \\
\text { LSLE: } 2.5 \\
{[2.5] / 21 \%}\end{array}$ & $\begin{array}{l}\text { aSLE OR } 12 \\
(1.6 \text { to } 92) \S \\
\text { LSLE OR } 19.4 \\
(2.6 \text { to } 143.1) \S \ddagger \ddagger\end{array}$ & $\mathrm{SDI}=0$ & $\begin{array}{l}\text { Age, musculoskeletal } \\
\text { manifestations }\end{array}$ \\
\hline Tarr et $a l^{17}$ & NS & 357 & $\begin{array}{l}19.1 \\
{[9.2,1-44] \dagger \dagger}\end{array}$ & $\begin{array}{l}\mathrm{SDI}=0: 22 \% \S \\
\mathrm{SDI}=1: 29 \% \S \\
\mathrm{SDI}=2: 17 \% \S \\
\mathrm{SDI}=3: 16 \% \S \\
\mathrm{SDI}=4: 7 \% \S \\
\mathrm{SDI}=5: 4 \% \S \\
\mathrm{SDI}=6-8: 5 \% \S\end{array}$ & $\begin{array}{l}\text { HR } 55.12 \\
\text { (19.15 to } 158.63)\end{array}$ & $\mathrm{SDl}<5$ & Med dose, sex \\
\hline
\end{tabular}

*Values are adjusted, unless otherwise noted.

†A few articles were unclear regarding all covariates; we have included only the covariates explicitly stated by the authors.

$\ddagger$ Publications with this footnote indicate different analyses based on data from the same cohort of patients, though specific patients included across studies likely differed. Two cohorts included in our review have multiple publications listed in this table.

§Values are SDI scores at end of follow-up or reported estimates based on SDI values at end of follow-up.

TCardoso et al (2008) did multiple analyses that are included in both continuous and binary sections of the table.

${ }^{* *}$ Publications with this footnote indicate different analyses based on data from the same cohorts of patients, though specific patients included across studies likely differed. Two cohorts included in our review have multiple publications listed in this table.

††Tarr et al (2017) label these values as describing the follow-up duration in their manuscript text but use these same values (to two decimal places, not shown here) to describe their cohort's disease duration.

†¥Unadjusted estimate.

AA, African-American; AMS, adjusted mean SLEDAl; AO, Asian-Oriental; APS, antiphospholipid syndrome; aSLE, adult-onset SLE; BILAG, British Isles Lupus Assessment Group; C, Caucasian; CCI, Charlson comorbidity index; cSLE, childhood-onset SLE; CV, cardiovascular; F, female; FN, First Nation, the predominant aboriginal peoples of Canada; H-PR, Hispanic (Puerto Rico); H-T, Hispanic (Texan); LLC, Lund Lupus Cohort; LSLE, late-onset SLE; M, male; med, medication; MLC, Montreal Lupus Cohort; NS, not stated; RR, relative risk; SDI, Systemic Lupus International Collaborating Clinics/American College of Rheumatology Damage Index; SES, socioeconomic status; SF-6D, short-form six-dimension health survey; SLAMR, Systemic Lupus Activity Measure-Revised; SLE, systemic lupus erythematosus; SLEDAI, Systemic Lupus Erythematosus Disease Activity.

\section{Assessment of study quality}

Most studies (85\%) analysed were of high quality as measured using the Newcastle-Ottawa Scale (online supplementaryappendix 4). ${ }^{13-2123-3032}$ All 21 studies scored high regarding selection of patients who were representative of the population of adults with SLE in each country. All studies relied on secure clinical records to determine SLE diagnoses and extent of organ damage. Study quality differed with regard to analysis and follow-up cohort retention. Analyses were rated as adequate in 15 studies that adjusted for age and at least one other factor related to mortality; ${ }^{13} 1516$ 18-21 2324 26-30 32 the remaining studies either were not age adjusted (three studies), ${ }^{14} 1731$ were only adjusted for age (two studies) ${ }^{525}$ or had no description of adjustment (one study) ${ }^{22}$ In eight studies, less than $20 \%$ of the cohort was lost to follow-up; $;^{1417192024-2630}$ four studies lost more than $20 \%$ to follow-up, ${ }^{5131532}$ and nine studies did not report losses to follow-up. ${ }^{16} 18$ 21-23 27-29 31 


\begin{tabular}{|c|c|c|c|}
\hline Publication & $\begin{array}{l}\text { Hazard ratio } \\
(95 \% \mathrm{Cl})\end{array}$ & $\begin{array}{l}\text { Hazard ratio } \\
(95 \% \mathrm{Cl})\end{array}$ & $\begin{array}{l}\% \text { weight from } \\
\text { random-effects } \\
\text { analysis }\end{array}$ \\
\hline Mok et al $(2005)^{29}$ & $\longmapsto$ & $3.65(1.52-8.76)$ & 0.69 \\
\hline Fernández et al $(2007)^{31}$ & -1 & $1.20(1.00-1.44)$ & 9.47 \\
\hline Cardoso et al $(2008)^{27}$ & 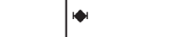 & $1.35(1.16-1.57)$ & 11.56 \\
\hline Urowitz et al $(2008)^{19}$ & 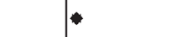 & $1.24(1.14-1.35)$ & 17.41 \\
\hline Chambers et al $(2009)^{7}$ & -1 & $1.40(1.14-1.72)$ & 8.18 \\
\hline Jonsen et al (2011) ${ }^{16}$ & - & $1.48(1.37-1.60)$ & 18.06 \\
\hline Gafter-Gvili et al $(2013)^{24}$ & 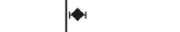 & $1.28(1.08-1.50)$ & 10.63 \\
\hline Telles et al $(2013)^{17}$ & $1 \bullet 1$ & $1.40(1.08-1.82)$ & 5.88 \\
\hline Bruce et al $(2015)^{25}$ & 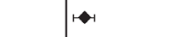 & $1.46(1.18-1.81)$ & 7.77 \\
\hline Joo et al $(2016)^{23}$ & $\rightarrow$ & $1.20(1.00-1.40)$ & 10.36 \\
\hline $\begin{array}{l}\text { Pooled studies } \\
\left(p=0.027, I^{2}=52.1 \%\right)\end{array}$ & $\Rightarrow$ & $1.34(1.24-1.44)$ & \\
\hline $\begin{array}{l}\text { Pooled studies without Mok } \\
\text { et } \mathrm{a}^{2^{29}}\left(p=0.087,\left.\right|^{2}=42.0 \%\right)\end{array}$ & 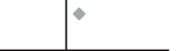 & $1.33(1.25-1.42)$ & \\
\hline 0 . & 10 & & \\
\hline
\end{tabular}

Figure 2 Forest plot of HRs for the association between organ damage (1-point increase in SDI) and mortality for studies included in the meta-analysis ( $\mathrm{n}=10$ studies). SDI, Systemic Lupus International Collaborating Clinics/American College of Rheumatology Damage Index.

\section{Mortality in patients with SLE}

In all of the studies reviewed, standardised mortality ratios (SMRs) or survival rates were reported for patients with SLE. Four studies reported SMRs for patients with SLE relative to the general population within a specific country (online supplementary appendix 5). ${ }^{16192030}$ The SMRs reported ranged from 2.4 over a 12-year period in a Swedish cohort, ${ }^{30} 2.9$ in a Korean cohort $^{20}$ over a 5-year period and 2.4 and 2.7 over 5-year and 10-year periods, respectively, in a German cohort. ${ }^{19}{\text { Urowitz et } a l^{16}}^{16}$ reported on a cohort of Canadian patients with SLE and estimated a 36-year overall SMR of 4.5 in patients with SLE compared with the general population. When this study population was stratified into cohorts based on time of study entry, the reported SMRs varied widely: the 1970 to 1979 and 1996 to 2005 entry cohorts had 10-year SMRs of 12.6 and 3.5, respectively. ${ }^{16}$

Eight studies reported survival rates; six studies reported 5-year survival rates (range: $87 \%$ to $99 \%$, in populations/ subpopulations from Germany, China, the USA, South Korea and Hungary), ${ }^{151719202632}$ and two studies reported 4-year and 12-year survival rates of 95\% ${ }^{23}$ (Latin America) and $80 \%^{30}$ (Sweden), respectively.

\section{Organ damage and mortality}

Table 1 summarises the key findings of the 21 included studies regarding organ damage and mortality (full data shown in online supplementary appendix 5). Baseline mean SDI scores ranged from 0.1 to 1.0 (SD range: 0.6 to 1.5$)$. Across studies, SDI was evaluated as a continuous variable or binary category to assess the association between organ damage and mortality; SDI was evaluated as a continuous variable in 14 studies and as a binary category (comparing risk of mortality at various SDI score cutoffs) in eight studies. One study evaluated SDI both as a continuous variable and a binary category (table 1$).^{24}$
Meta-analysis of organ damage and mortality

SDI evaluated as a continuous variable

Fourteen studies evaluated SDI as a continuous predictor of mortality. ${ }^{5}$ 13-16 20-22 24 26-28 3132 Of these, 10 performed time-to-event analyses and reported the risk of death per 1-unit increase in SDI. These represent the group of studies that were pooled for meta-analysis. Figure 2 is a forest plot of HRs across the 10 studies included in the meta-analysis. Findings from meta-analysis suggest a $34 \%$ increased risk of death for each 1-point increase in SDI score (pooled HR 1.34, 95\% CI: 1.24 to 1.44, p<0.001; Cochrane $\mathrm{Q} \mathrm{p}=0.027, \mathrm{I}^{2}=52.1 \%$ ).

To account for study heterogeneity, the data were analysed excluding Mok et al, ${ }^{26}$ which evaluated 213 Chinese patients over the course of 13 years and reported a notably greater risk of mortality per 1-unit SDI increase than other studies (HR 3.65, 95\% CI: 1.52 to 8.76, $\mathrm{p}=0.004$ ). The exclusion of the Mok et $a t^{26}$ study reduced heterogeneity to moderate (Cochrane $Q \mathrm{p}=0.087, \mathrm{I}^{2}=42.0 \%$ ) but had minimal impact on pooled HR (pooled HR of mortality for a 1-unit increase in SDI=1.33 (95\% CI: 1.25 to $1.42, \mathrm{p}<0.001$ ), figure 2 ).

A funnel plot representing HR of organ damage and mortality in patients with SLE was used to evaluate population bias (online supplementary appendix 6). Visual inspection of the funnel plot (excluding Mok et $a l^{26}$ ) identified marginal asymmetry, suggesting publication bias, whereas an Egger's test did not suggest publication bias $(p>0.05)$. These findings should be interpreted with consideration given the few studies included in the meta-analysis. $^{36}$

In addition to the studies summarised above in the meta-analysis, three studies that evaluated SDI as a continuous variable reported ORs for a 1-point increase in SDI; these ORs were 1.19 (95\% CI: 1.02 to $1.39, \mathrm{p}=0.031),{ }^{32}$ $1.70(95 \% \text { CI: } 0.80 \text { to } 3.70, \mathrm{p}>0.05)^{31}$ and $19.70(95 \%$ CI: 5.30 to $72.50, \mathrm{p}<0.001)^{15}$ (figure 3 ). The largest likelihood of mortality observed suggests approximately 20-fold increased odds of mortality for a 1-point increase in organ damage, among 1010 patients evaluated in South Korea. ${ }^{15}$

\section{SDI evaluated as binary categories}

Of eight analyses that evaluated SDI as binary categories, two assessed the odds of death associated with any organ damage compared with no organ damage $(\mathrm{SDI}=0$ vs SDI $>0),{ }^{23} 25$ and four studies, ${ }^{17} 182430$ compared the risk of mortality by various $\mathrm{SDI}$ categories $(\mathrm{SDI}<2$ vs $\mathrm{SDI} \geq 2$; $\mathrm{SDI}<3$ vs $\mathrm{SDI} \geq 3$ or $\mathrm{SDI}<5$ vs $\mathrm{SDI} \geq 5$ ) (figure 3 ). PonsEstel et $a l^{23}$ studied 1214 patients from Latin America (including 537 mestizo, 507 white and 152 African-Latin American patients) who had been diagnosed with SLE within the previous 2 years. Over a median follow-up period of 20 months, Pons-Estel et al reported increased odds of death associated with any organ damage, SDI $\geq 1$ vs $\mathrm{SDI}=0$, in patients with SLE (OR 2.8, 95\% CI: 1.2 to 6.4). In Spain, Martínez-Barrio et $a l^{25}$ studied 276 patients with adult-onset SLE and 77 patients with late-onset 


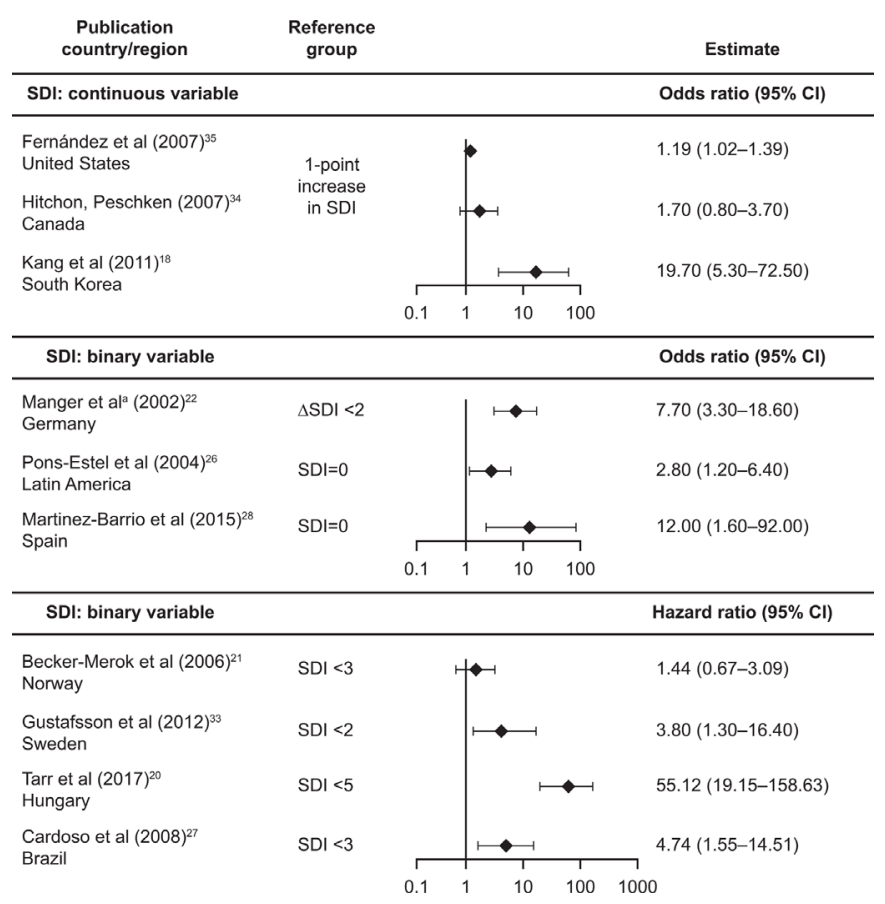

Figure 3 Forest plot of association between organ damage and mortality in remaining studies with SDI as a continuous or binary variable. ${ }^{a}$ Reports the relative risk. SDI, Systemic Lupus International Collaborating Clinics/American College of Rheumatology Damage Index.

SLE over a mean 26-year follow-up period and reported significantly increased odds of death associated with any organ damage, $\mathrm{SDI}=0$ vs SDI $>0$ (OR 12, 95\% CI: 1.6 to 92, $\mathrm{p}=0.01$ ). Other studies reported the odds of death associated with having an $\mathrm{SDI} \geq 2$ vs $\mathrm{SDI}<2$ (208 patients from Sweden; HR 3.80, 95\% CI: 1.30 to $16.40, \mathrm{p}=0.01),{ }^{30} \mathrm{SDI} \geq 3$ vs $\mathrm{SDI}<3$ (105 patients from Brazil; HR 4.74, 95\% CI: 1.55 to $14.51, \mathrm{p}=0.006)^{24}$ or $\mathrm{SDI} \geq 5$ vs $\mathrm{SDI}<5$ ( 357 patients from Hungary; HR 55.12, 95\% CI: 19.15 to 158.63 , p<0.001) ${ }^{17}$ In the study by Becker-Merok and Nossent ${ }^{18}$ from Norway $(\mathrm{n}=158)$, the authors reported a positive association between greater organ damage and increased mortality risk (SDI $\geq 3$ vs $\mathrm{SDI}<3$, HR 1.44, 95\% CI: 0.67 to 3.09, $\mathrm{p}=0.42$ ), although this was not statistically significant.

Two studies identified that additional organ damage accrued during study follow-up was significantly associated with increased risk of mortality. ${ }^{21}{ }^{24}$ In the study by Cardoso et $a l^{24}$ including 105 patients from Brazil, any increase in SDI during follow-up was associated with a significant increase in risk of mortality compared with no change in SDI (HR 5.1, 95\% CI: 1.99 to 13.03, $\mathrm{p}=0.001){ }^{24}$ Similarly, in 338 patients in Germany, Manger et $a l^{19}$ found nearly eightfold increase in mortality with organ damage accrual $(\Delta \mathrm{SDI} \geq 2$ vs $\Delta \mathrm{SDI}<2$ from the first to the third year of follow-up; relative risk $7.7,95 \%$ CI: 3.3 to 18.6, $\mathrm{p}<0.0001$ ).

Danila et $a l^{29}$ evaluated the association between specific organ damage and mortality in a multi-ethnic cohort of 635 patients from the USA. This analysis identified significantly greater risk of earlier death for patients with SLE who had renal damage compared with those without renal damage (HR 1.65, 95\% CI: 1.03 to $2.66, \mathrm{p} \leq 0.05$ ). There was, however, no significant association between cardiovascular damage and earlier death (HR 1.55, 95\% CI: 0.94 to $2.56, \mathrm{p}>0.05) .{ }^{29}$

\section{DISCUSSION}

In this meta-analysis of 10 studies from four continents that evaluated the risk of death among individuals with SLE who had organ damage, we identified that each 1-unit increase in SDI was associated with a $34 \%$ increased risk of death. We also identified an increased risk and consistent association between increasing organ damage and greater mortality in all 21 articles that were retained for this systematic review. The increased risk of death associated with organ damage was present across studies from various countries and different patient populations, as well as across studies that used varying epidemiological and statistical methods. It is notable that the association between incremental organ damage and mortality was largely consistent, despite the differences in healthcare delivery systems and life expectancy across countries. The magnitude of the estimated associations between organ damage and mortality varied and may be attributable to differences in how SDI was modelled (eg, as a continuous variable or binary category), the thresholds of SDI used for analysis, and the choice of covariates accounted for when multivariable analyses were performed.

From 1950 to 2000, the 10-year survival rate in patients with SLE has improved from $63 \%$ to $91 \%,{ }^{37}$ and it is postulated that improvements in patient management are responsible for these gains in survival. Despite such positive achievements, it is clear that further gains are needed. Optimising treatment to obtain good control of SLE disease is important for reducing organ damage and mortality risk. For treatment of patients with SLE, the Treat to Target (T2T)/SLE international task force has outlined several overarching principles, including optimising disease control, minimising comorbidities, reducing drug toxicities to enable long-term survival, preventing organ damage and enhancing health-related quality of life. ${ }^{38}$

The T2T task force highlighted the importance of minimising glucocorticoid dosages and eliminating them entirely, if possible. As with other rheumatological diseases, studies of patients with SLE have shown that greater systemic steroid dosage is associated with increasing damage to multiple body systems. ${ }^{8}$ New treatments for SLE that would allow steroid sparing would be clinically important for reducing organ damage and improving outcomes for patients.

To our knowledge, this is the first meta-analysis informed by a systematic literature review to quantitatively synthesise published literature on SLE-related organ damage measured by SDI and its association with mortality. We observed some heterogeneity in the studies included in these meta-analyses. However, sensitivity analyses demonstrated that exclusion of one study, ${ }^{26}$ 
which reported a notably greater HR than other studies, reduced heterogeneity with minimal impact on pooled HR. The search criteria excluded studies published in languages other than English, which may represent a bias in reporting; however, there is limited evidence to suggest language bias with this approach. Morrison $e t a l^{39}$ conducted a comprehensive literature review and found no evidence of systematic bias from the use of language restrictions in systematic review-based meta-analyses. Because our search strategy was restricted to the inclusion of publications identified between 2000 and 2017, if there are relevant studies published after 2017, they are not included in this analysis. This is a limitation of our work; however, because of the consistency of our findings across a large number of studies and geographical regions, and long patient follow-up periods for included studies ranging from a few years to 50 years, it is unlikely that studies published after 2017, or in languages other than English, would significantly affect the observed association between organ damage and mortality. An update on the available evidence in the next few years would allow an expanded assessment of the effect of newer treatments on organ damage and how this may be associated with mortality in patients with SLE. In the current study, we were unable to summarise across all identified studies using meta-analytic methods because of variations in methods used across studies. Ten of 21 studies were combined in meta-analysis and the remaining 11 studies were summarised qualitatively. The consistency of the results across multiple study design types and varying methods of analyses corroborates our overall conclusions.

A previous qualitative review, based on studies prior to 2012, supports our findings. A systematic review by Sutton $e t a t^{t 0}$ included five studies examining the association between organ damage and risk of death in patients with SLE. All five studies confirmed a positive association between higher SDI scores and mortality. ${ }^{40}$ For example, one study included in the Sutton meta-analysis found a significantly higher 10 -year mortality rate $(25 \%)$ in patients with early damage (SDI $\geq 1$ at enrolment) than in patients with no early damage $(7.3 \%, \mathrm{p}<0.001){ }^{40}$

Biological therapy has recently become available for the treatment of SLE. ${ }^{41}$ However, none of the studies we evaluated examined how specific drugs may mediate the association between organ damage and mortality, perhaps because of the relatively short period since biologics were introduced for SLE. Thus, future studies assessing the impact of various SLE therapies, including steroids and biologic treatment, on organ damage and consequent mortality will be needed.

\section{CONCLUSIONS}

Organ damage in patients with SLE is consistently associated with increased mortality across studies from around the world that evaluated different patient populations using various study methods. Novel therapies that are potentially disease modifying and steroid sparing could reduce organ damage, improve overall outcomes and decrease mortality for patients with SLE.

\section{Author affiliations}

${ }^{1}$ Department of Epidemiology, Johns Hopkins Bloomberg School of Public Health, Baltimore, Maryland, USA

${ }^{2}$ Center for Drug Safety and Effectiveness, Johns Hopkins Bloomberg School of Public Health, Baltimore, Maryland, USA

${ }^{3}$ Carle Illinois College of Medicine, University of Illinois at Urbana-Champaign, Champaign, Illinois, USA

${ }^{4}$ Inflammation \& Autoimmunity, AstraZeneca, Cambridge, UK

${ }^{5}$ Center for Population Health IT, Department of Health Policy and Management, Johns Hopkins Bloomberg School of Public Health, Baltimore, Maryland, USA

${ }^{6}$ Department of Medicine, Johns Hopkins Bloomberg School of Public Health, Baltimore, Maryland, USA

${ }^{7}$ BioPharmaceuticals Medical, AstraZeneca, Gaithersburg, Maryland, USA

${ }^{8}$ Division of General Internal Medicine, Johns Hopkins University School of Medicine, Baltimore, Maryland, USA

Acknowledgements Medical writing and editing support was provided by Bryony Jones, PhD, and Ellen Stoltzfus, PhD, of JK Associates, Inc, in accordance with Good Publication Practice (GPP3) guidelines (http://www.ismpp.org/gpp3).

Contributors IBMW, DHL, HN, HJK, JCT, XW, BD, GCA and ERH were involved in the conception and design of the review. IBMW and $\mathrm{DHL}$ developed the search strategy and performed study selection. IBMW, DHL and 00 extracted data from included studies. IBMW, DHL, HN, HJK, 00, JCT, XW, BD, GCA and ERH were involved in the data analysis. All authors (IBMW, DHL, HN, HJK, 00, JCT, XW, BD, GCA and ERH) were involved in the interpretation and discussion of results. All authors drafted the manuscript, contributed to the drafting of the review and/or revised it critically for important intellectual content. All authors approved the final version of the article. All authors had access to all of the data in the study and can take responsibility for the integrity of the data and the accuracy of the data analysis. ERH is the guarantor.

Funding AstraZeneca provided funding for this systematic review and the medical writing support.

Competing interests All authors have completed the ICMJE uniform disclosure form at http://www.icmje.org/coi_disclosure.pdf and declare: no support from any organisation for the submitted work. HN was an employee of AstraZeneca when this work was performed. HJK is a shareholder of GlaxoSmithKline. XW, BD and ERH are employees of AstraZeneca. GCA is Chair of the FDA's Peripheral and Central Nervous System Advisory Committee, has served as a paid advisor to IQVIA, serves on the advisory board of MesaRx Innovations, is a member of OptumRx's National P\&T Committee and holds equity in Monument Analytics, a healthcare consultancy whose clients include the life sciences industry as well as plaintiffs in opioid litigation. This arrangement has been reviewed and approved by Johns Hopkins University in accordance with its conflict of interest policies.

Patient consent for publication Not required.

Provenance and peer review Not commissioned; externally peer reviewed.

Data availability statement All data relevant to the study are included in the article or uploaded as supplementary information. No additional data available.

Open access This is an open access article distributed in accordance with the Creative Commons Attribution Non Commercial (CC BY-NC 4.0) license, which permits others to distribute, remix, adapt, build upon this work non-commercially, and license their derivative works on different terms, provided the original work is properly cited, appropriate credit is given, any changes made indicated, and the use is non-commercial. See: http://creativecommons.org/licenses/by-nc/4.0/.

\section{REFERENCES}

1 Maidhof W, Hilas O. Lupus: an overview of the disease and management options. P T 2012;37:240-9.

2 Taraborelli M, Cavazzana I, Martinazzi N, et al. Organ damage accrual and distribution in systemic lupus erythematosus patients followedup for more than 10 years. Lupus 2017;26:1197-204.

3 Mak A, Cheung MW-L, Chiew HJ, et al. Global trend of survival and damage of systemic lupus erythematosus: meta-analysis and metaregression of observational studies from the 1950s to 2000s. Semin Arthritis Rheum 2012;41:830-9. 
4 Gladman DD, Urowitz MB, Rahman P, et al. Accrual of organ damage over time in patients with systemic lupus erythematosus. $J$ Rheumatol 2003;30:1955-9.

5 Chambers SA, Allen E, Rahman A, et al. Damage and mortality in a group of British patients with systemic lupus erythematosus followed up for over 10 years. Rheumatology 2009;48:673-5.

6 Carter EE, Barr SG, Clarke AE. The global burden of SLE: prevalence, health disparities and socioeconomic impact. Nat Rev Rheumatol 2016;12:605-20.

7 Al Sawah S, Zhang X, Zhu B, et al. Effect of corticosteroid use by dose on the risk of developing organ damage over time in systemic lupus erythematosus-the Hopkins lupus cohort. Lupus Sci Med 2015;2:e000066

8 Thamer M, Hernán MA, Zhang Y, et al. Prednisone, lupus activity, and permanent organ damage. J Rheumatol 2009;36:560-4.

9 McElhone K, Abbott J, Teh LS. A review of health related quality of life in systemic lupus erythematosus. Lupus 2006;15:633-43.

10 Moher D, Liberati A, Tetzlaff J, et al. Preferred reporting items for systematic reviews and meta-analyses: the PRISMA statement. PLoS Med 2009;6:e1000097.

11 Hammond ER MI, Lin DH, et al. SAT0428 association between organ damage and health-related quality of life in systemic lupus erythematosus (SLE): a systematic review. Ann Rheum Dis 2018;77:1073-4.

12 Wells GA, Shea B, O'Connell D, et al. The Newcastle-Ottawa scale (NOS) for assessing the quality of nonrandomised studies in metaanalyses, 2011. Available: http://www.ohri.ca/programs/clinical_ epidemiology/oxford.asp

13 Jönsen A, Clarke AE, Joseph L, et al. Association of the Charlson comorbidity index with mortality in systemic lupus erythematosus. Arthritis Care Res 2011;63:1233-7.

14 Telles RW, Lanna CCD, Souza FL, et al. Causes and predictors of death in Brazilian lupus patients. Rheumatol Int 2013;33:467-73.

15 Kang KY, Kwok S-K, Ju JH, et al. The causes of death in Korean patients with systemic lupus erythematosus over 11 years. Lupus 2011;20:989-97.

16 Urowitz MB, Gladman DD, Tom BDM, et al. Changing patterns in mortality and disease outcomes for patients with systemic lupus erythematosus. J Rheumatol 2008;35:2152-8.

17 Tarr T, Papp G, Nagy N, et al. Chronic high-dose glucocorticoid therapy triggers the development of chronic organ damage and worsens disease outcome in systemic lupus erythematosus. Clin Rheumatol 2017;36:327-33.

18 Becker-Merok A, Nossent HC. Damage accumulation in systemic lupus erythematosus and its relation to disease activity and mortality. $J$ Rheumatol 2006;33:1570-7.

19 Manger K, Manger B, Repp R, et al. Definition of risk factors for death, end stage renal disease, and thromboembolic events in a monocentric cohort of 338 patients with systemic lupus erythematosus. Ann Rheum Dis 2002;61:1065-70.

20 Joo YB, Park S-Y, Won S, et al. Differences in clinical features and mortality between childhood-onset and adult-onset systemic lupus erythematosus: a prospective single-center study. J Rheumato 2016;43:1490-7.

21 Gafter-Gvili A, Leibovici L, Molad Y. Elevation of inflammatory markers in patients with systemic lupus erythematosus is associated with poorer outcome. Biomed Pharmacother 2013;67:48-52.

22 Bruce IN, O'Keeffe AG, Farewell V, et al. Factors associated with damage accrual in patients with systemic lupus erythematosus: results from the systemic lupus international collaborating clinics (SLICC) inception cohort. Ann Rheum Dis 2015;74:1706-13.
23 Pons-Estel BA, Catoggio LJ, Cardiel MH, et al. The GLADEL multinational Latin American prospective inception cohort of 1,214 patients with systemic lupus erythematosus: ethnic and disease heterogeneity among "Hispanics". Medicine 2004;83:1-17.

24 Cardoso CRL, Signorelli FV, Papi JAS, et al. Initial and accrued damage as predictors of mortality in Brazilian patients with systemic lupus erythematosus: a cohort study. Lupus 2008;17:1042-8.

25 Martínez-Barrio J, Ovalles-Bonilla JG, López-Longo FJ, et al. Juvenile, adult and late-onset systemic lupus erythematosus: a long term follow-up study from a geographic and ethnically homogeneous population. Clin Exp Rheumatol 2015;33:788-94.

26 Mok CC, Mak A, Chu WP, et al. Long-Term survival of southern Chinese patients with systemic lupus erythematosus: a prospective study of all age-groups. Medicine 2005;84:218-24.

27 Lopez R, Davidson JE, Beeby MD, et al. Lupus disease activity and the risk of subsequent organ damage and mortality in a large lupus cohort. Rheumatology 2012;51:491-8.

28 Fernández M, Alarcón GS, McGwin G, et al. Using the short form $6 \mathrm{D}$, as an overall measure of health, to predict damage accrual and mortality in patients with systemic lupus erythematosus: XLVII, results from a multiethnic US cohort. Arthritis Rheum 2007;57:986-92.

29 Danila MI, Pons-Estel GJ, Zhang J, et al. Renal damage is the most important predictor of mortality within the damage index: data from LUMINA LXIV, a multiethnic US cohort. Rheumatology 2009;48:542-5.

30 Gustafsson JT, Simard JF, Gunnarsson I, et al. Risk factors for cardiovascular mortality in patients with systemic lupus erythematosus, a prospective cohort study. Arthritis Res Ther 2012;14:R46.

31 Hitchon CA, Peschken CA. Sm antibodies increase risk of death in systemic lupus erythematosus. Lupus 2007;16:186-94.

32 Fernández M, Alarcón GS, Calvo-Alén J, et al. A multiethnic, multicenter cohort of patients with systemic lupus erythematosus (SLE) as a model for the study of ethnic disparities in SLE. Arthritis Rheum 2007;57:576-84.

33 Higgins JPT, Thompson SG. Quantifying heterogeneity in a metaanalysis. Stat Med 2002;21:1539-58.

34 Higgins JPT, Thompson SG, Deeks JJ, et al. Measuring inconsistency in meta-analyses. BMJ 2003;327:557-60.

35 Bowden J, Tierney JF, Copas AJ, et al. Quantifying, displaying and accounting for heterogeneity in the meta-analysis of RCTs using standard and generalised Q statistics. BMC Med Res Methodol 2011;11:41.

36 Lau J, loannidis JPA, Terrin N, et al. The case of the misleading funnel plot. BMJ 2006;333:597-600.

37 Kaul A, Gordon C, Crow MK, et al. Systemic lupus erythematosus. Nat Rev Dis Primers 2016;2:16039.

38 van Vollenhoven RF, Mosca M, Bertsias G, et al. Treat-to-target in systemic lupus erythematosus: recommendations from an international Task force. Ann Rheum Dis 2014;73:958-67.

39 Morrison A, Polisena J, Husereau D, et al. The effect of Englishlanguage restriction on systematic review-based meta-analyses: a systematic review of empirical studies. Int J Technol Assess Health Care 2012;28:138-44.

40 Sutton EJ, Davidson JE, Bruce IN. The systemic lupus international collaborating clinics (SLICC) damage index: a systematic literature review. Semin Arthritis Rheum 2013;43:352-61.

41 Touma Z, Gladman DD. Current and future therapies for SLE: obstacles and recommendations for the development of novel treatments. Lupus Sci Med 2017;4:e000239. 